\title{
The PowerPoint Nation: Branding an Imagined Commodity
}

\author{
GÖRAN BOLIN\&PER STAHLBERG \\ Södertörn University, SE-141 89 Huddinge, Sweden. Email: goran.bolin@sh.se
}

\begin{abstract}
In the formation of the modern nation state and the social imaginary of nationalism in the nineteenth century, the media and representational practices have, among most scholars, been ascribed a prominent position. The question is, however, how have changes in media technologies, from mass media to digital and interactive personal media, impacted on the national imaginaries over the past few decades? This article discusses what happens with the social imaginaries when national(ist) symbols are reproduced through the medium of PowerPoint, as one of the main tools for constructing images of the nation in nation-branding campaigns, i.e. promotional campaigns initiated by governments in conjunction with corporate actors with the aim of producing an attractive image of a country for foreign investors and tourists. It is concluded that the representational technology of PowerPoint produces a nation as an imagined commodity rather than an imagined community.
\end{abstract}

\section{Introduction}

In the formation of the modern nation state in the nineteenth century, the media and representational practices have been ascribed a prominent position. In his seminal work on the origin and establishment of nationalism, Benedict Anderson (2006 [1991]) described how 'print capitalism' was a prerequisite for the formation of national consciousness and an imagined community where citizens could feel that they belonged to a greater whole. Other scholars have pointed to other media forms of importance for 'inventing' the traditions on which the modern nation state is built (e.g. Hobsbawm and Ranger 1983), for example music, most notably national anthems (Bohlman 2004), art, especially landscape painting (Adams and Robins 2000), and, importantly, the media that were introduced to schoolchildren with the launch of the national educational systems in Europe in the mid-1800s (Gellner 1983).

The ingenuity of Anderson's approach was to reframe nationalism from being studied as a form of political mobilisation to being understood as a subject of cultural imagination, and he stressed that it had to be understood as a mode of thinking: the 
nation had to be formed in the mind before it could become influential in everyday practice; it had to be imagined, formed in a collective 'social imaginary' (Taylor 2002).

Anderson as well as many of his later interpreters, have stressed the role of the mass media in these processes - in Anderson's case the novel and the newspaper. However, as Akhil Gupta (2008) has pointed out as a side-note to his critique of Anderson's insufficient attention to time in his theory of nationalism, there is something peculiar about the importance that Anderson - and those who have adopted his theory to explain more modern forms of nation building - gives to the novel and the newspaper:

If nationalism as a form of imagined community was forged through specific technologies of communication and transportation, how could a massive revolution in those technologies [...] have left forms of imagining the nation unaffected? (Gupta 2008, 276)

In this article we will discuss the consequences of a change of media technology for representing 'the nation' and constructing its social imaginary. Since each medium has specific characteristics and abilities to represent and to narrate, we should, in line with Gupta's observation, expect changes in the ways in which the nation is represented, depending on which medium is the source of the imaginary. By medium we mean both the specific technology and its organisational form, and we will focus on a quite banal medium that most scholars use, but one that is rarely discussed in media research: presentation software (PowerPoint, Keynote, Prezi, etc.). Furthermore, we shall discuss the consequences of the use of presentation software in relation to an activity that involves extensive use of signifiers of 'the nation', namely, the activity of nation branding; the phenomenon by which governments engage in self-conscious activities aimed at producing a certain image of the nation-state in question by moulding symbols and signs of 'the nation' into commercial messages aiming to attract tourists, investors and corporate finance (Bolin and Ståhlberg 2010, 82).

As a point of departure we will look at the way in which imaginaries of the nation are created, in order to rethink some features in the literature on nationalism. We will start by revisiting Benedict Anderson's understanding of the importance of media technologies for the formation of imagined communities, proceeding with a discussion of how presentational software (in this case PowerPoint) fits with this theory. Next, we discuss the role of newspapers, novel and presentational software such as PowerPoint technologies, representational forms and generic conventions in the constructions of national imaginaries, in order to summarise our reflections on the ways in which media technologies affect the construction of imaginaries of the nation in the conclusions.

\section{Nationalism from Print to Digital Capitalism}

In one of the most cited paragraphs of Imagined Communities, Anderson explains the specific kind of imaginary that has to emerge in order for nationalism to occur. That 
is the idea of the nation as a solid community, 'a sociological organism moving calendrically through homogenous empty time' (Anderson 2006 [1991], 26). No American, he says, will have any idea of what all other millions of Americans are up to at any one moment, but everyone will have a 'complete confidence in their steady, anonymous, simultaneous activity’ (Anderson 2006 [1991], 26).

The key word here is 'simultaneous,' and what brings people to be connected in time is, following Anderson's argument, determined by revolutionary developments of communication technologies. Print-capitalism laid a foundation for a national consciousness to emerge in various ways, not least the evolvement of standardised vernacular print languages by which national histories and traditions could be represented. However, with regard to simultaneity, two forms of media commodities made possible by print capitalism are central in Anderson's argument: the novel and the newspaper. It is from particular features of these two early commodities that the modular form of national consciousness is made possible.

The novel and the newspaper are, in Anderson's account, generating consciousness of the nation in two significantly different ways (cf. Gupta 2008, 272). The novel is constructing social community in the text, through a story in which things are going on 'in the meantime', linking otherwise unrelated characters and events with a social entity or a particular place by simultaneity. The newspaper has this quality as well, connecting completely unrelated pieces of information and events by 'calendrical' coincidence - that is, by the date at the top of the page.

The newspaper, however, also has a second role of constructing social imaginaries, by the act of reading. The newspaper created an 'extraordinary mass ceremony' since, each day, the newspaper is consumed in silent privacy, by readers who are completely confident that thousands of other anonymous people, almost simultaneously, are doing the same (Anderson 2006 [1991], 35). The 'simultaneity' in this collective act of reading is not confined to literary imagination, it is rather a matter of this specific cultural technology's infrastructural quality of synchronising its audience. In this regard the newspaper is similar to other devices of the industrial age, such as the clock and the calendar (Mihelj 2011, 142f).

Anderson adds three features to this synchronising function in his revised second edition of Imagined communities: the census, the map and the museum. If the novel and the newspaper produces the imaginary of the nation in time, the census and the map constructs the nation in space by marking out its territorial boundaries, while the museum - maybe most importantly national museums - could be said to construct the imaginary of the nation in space and time, as they preserve treasures belonging to a specific (national) territory, and also demarcate that historical heritage over time. These additions are important also for understanding Anderson's (1998) later introduction of the concept of seriality, which distinguishes between 'unbound seriality', based in self-identification as a principle for national belonging, and 'bound seriality', roughly corresponding to that ascribed national identity that is established through, for example, the census.

Later media commodities, such as radio and television, have admittedly also privileged synchronous communication and simultaneity in the sense of constructing 
'in the meantime'-narratives and by synchronising audience experience. Maybe even more so, since the very technology of broadcasting forced audiences to watch or listen at the same time - or not at all. But how can we understand the nation in relation to asynchronous digital media, which are less suited for constructing 'calendrical coincidence' or 'in the meantime'-ness And what role does changes in organisational form play when we move from the large scale, bureaucratic production modes of the mass media to the smaller scale and more loosely organised settings of digital personal media?

Few scholars have questioned whether radical changes in media technologies or their organisational forms have altered what Anderson regarded as the basic conditions for imagining the nation. One reason might be that most scholarship on digital media and the nation has focused on the representation of nations in text or images, or the communication of the idea and politics of the nation, rather than on the morphology or media technologies as such. However, Thomas Hylland Eriksen, in his reflections on Gellner's work for the internet age, emphasises the social character of the medium, arguing that rather than 'being a "disembedding" technology, the Internet has in fact proven to be a "re-embedding" technology', providing the technological means to strengthen dispersed national identities (Eriksen 2007, 7). Similarly, Niki Akhavan (2014) has studied new forms of mobilisation of Iranian identities on the internet, and Ingrid Therwath (2012) the transnational practices of Hindu nationalism through the web. In Media Nations, Sabina Mihelj (2011) brings up a number of trends and developments of recent decades, which rather obviously should affect the construction of national imaginaries: increasingly fragmented media landscapes, a globalised media industry, an increased focus on the consumer rather than the citizen. Despite all these new conditions, she argues, 'nation and nationalism show little signs of fading significance' (Mihelj 2011, 165). Similarly, Oren Soffer (2013) does recognise that the internet and other digital technologies privilege asynchronous communication and do not produce simultaneity, yet he emphasises that national discourse thrives and prevails in 'banal' forms on the web (cf. Billig 1995). This is of course true in the sense that the representation of 'nations' has hardly vanished. However, the centrality that Anderson saw in commodities of early print capitalism related to their form and structure, of the novel and the newspaper as media technologies converging with a specific mode of capitalist production. It could certainly be the case that representation of communities remains abundant and similar, while the underlying morphology has radically changed and thereby transformed the very modular idea of the nation.

Anderson, just as those who have studied music, art, literature, as the technologies by which the nation is formed discursively, mainly points to mass media technologies (e.g. print, cinema, television and radio). When nation-states in the early twenty-first century get drawn into commercial branding campaigns, these are also the media forms focused on by nation branding researchers (e.g. Aronczyk 2013; Kaneva 2012; Surowiec 2016; Valaskivi 2016; Volcic and Andrejevic 2015). This is somewhat strange, since new nationalism research has indeed noted the changes in media technologies and analysed internet-based nationalisms. We have elsewhere insisted 
on the need to pay closer attention to other kinds of media, since branding in addition to mass media adopts the media of public relations and advertising such as billboard advertising, commercials and event marketing, but also 'native content' in specialised media such as in-flight magazines, tourist brochures, etc. (Bolin and Ståhlberg 2010). More importantly, in the initial phases of nation-branding campaigns, at the moment when national imaginaries are constructed, quite different kinds of media are adopted, which cannot be considered mass media in the usual sense, for example, the brand book (Aronczyk 2013, 77; Bolin and Ståhlberg 2015), but also presentational software (e.g. PowerPoint, Keynote, Prezi, etc.).

Our exclusive concern here is with PowerPoint, which we will use as shorthand for all presentational software. Our interest lies in the way this medium is used to produce national imaginaries in the initiation of nation branding campaigns. We will argue that the specific character of PowerPoint technology and the way that PowerPoint communication is organised in the early stages of nation branding campaigns, have an impact on the imaginaries of the nation also in later campaign stages. PowerPoint and other presentation tools are media that have received little attention in media research in general, which might seem strange, given the fact that they have become widespread technologies since the launch of PowerPoint in 1987 (Yates and Orlikowski 2007). As a presentation tool, PowerPoint has become naturalised in diverse settings within education, corporate business, academic research and urban planning (Tufte 2003; Yates and Orlikowski 2007; Knoblauch 2008; Stark and Paravel 2008). Despite its short history, PowerPoint has affected the working practices within many of these areas - indeed converged with postindustrial modes of production. Much of the research into PowerPoint practice has focused on the cognitive, emotional and social constraints of the medium (Kernbach et al. 2015), although some have also pointed to its affordances (Stark and Paravel 2008).

In addition to being a rhetorical instrument (Kjeldsen 2006), PowerPoint is a structuring technology, with a specific morphology of its own (Stark and Paravel 2008). In many instances, PowerPoint masks itself as a presentation, while it might as well be said to have been developed into the very result of the work carried out within marketing divisions and organisational administration. If, previously, the marketing department delivered a written report or a memo to the corporate board, and then made a presentation of it with the aid of PowerPoint, today there is no report, and the actual result that the board gets is a printed deck of slides (Yates and Orlikowski 2007).Furthermore, the slide shows take on a life of their own after first being presented, as they circulate on corporate web pages, or on special platforms such as slideshare.net and are then further distributed on social networking sites such as Linkedin.com and Facebook.com, forming a repository of images and bullet points, with the possibility of being reused by others in new combinations.

Several researchers have argued that the PowerPoint presentation does not constitute a complete whole. It cannot stand by itself, but has to be understood contextually to a much larger extent than most other media genres. What that context should be varies between scholars. For Knoblauch (2008), it is the live 
presentation as such, in which the technology interacts with an audience and a presenter. Yates and Orlikowski (2007) regard the organisation in which PowerPoint is produced as the contextual unit of analysis. Stark and Paravel (2008) adopt a larger perspective and focus on political issues, topical for a certain public, as the context for which a particular presentation is demonstrated and circulated. When it comes to PowerPoint in relation to nation branding, the context could be extended even further because each PowerPoint is not only linked to its immediate local project context of involved producers and other actors, but also to previous campaigns and even to the whole international field of branding as such. Outside any context of promotional culture and practice, a PowerPoint presentation on nation branding would be fundamentally incomprehensible.

In the following sections we will, therefore, back up our argument by discussing the similarities and how the organisational, representational and generic forms of the novel, the newspaper and PowerPoint frame the creation of social imaginaries of 'the nation'.

\section{The Novel, the Newspaper and PowerPoint}

If we contrast the presentational medium of PowerPoint with the novel and the newspaper, we will find some significant differences in the technological features and generic and narrative potentials that makes PowerPoint less effective as a producer of nationalist imaginaries among wider populations, despite the extensive use of national symbols. In terms of generic conventions, the novel gradually developed its narrative form in the nineteenth century, characterised by the disruption of equilibrium at the beginning of the text and its restoration at the end. The novel also bears the clear marks of mechanical print culture, with the text fixated on the printed pages, allowing for very little manipulation by its reader. In that sense, the novel and the printed newspaper are firmly anchored within 'the Gutenberg parenthesis' (Pettitt 2007), that is, the period during which literary texts became one with their technological medium of representation: the book and the newspaper. As Walter Ong (2002 [1982], 115ff) has shown, the printing press, and the printed word, receive another type of authority compared with texts in chirographic culture. Some of this authority remains within the PowerPoint medium - the professional layout and the reproducibility bear the mark of print culture. But PowerPoint, even when in the form of a brand book, produces a different type of seriality that yields a different narrative organisation of text.

When analysing any PowerPoint collection we can see that it creates its own unique genre in at least two ways: as a type of social practice and as a type of textual expression. First, the social practice genre is a concept central to the analysis of Yates and Orlikowski who, through this concept, refer to a 'socially recognised type of communicative action' that occurs in 'everyday activities' of social subjects (Yates and Orlikowski 2007, 69; see also Knoblauch 2008). Second, the social and action-oriented genres described in organisation theory can be set in relation to the textual genres of literature and cinema (Das et al. 2013), especially if one is to 
compare PowerPoint slides to the novel, or the newspaper. Such genres are not practice-oriented as such, but refer more to the frameworks of knowledge within which social action takes place. In that sense, the sequencing of PowerPoint slides follows a generic pattern, developed in social practice and expressed in textual form.

Genres are characterised by specific narrative styles, and the brand book genre follows such a specific style of narration. It is not always explicitly spelled out, yet it can be revealed in a basic narrative analysis. Narratives are tools for structuring meaning and the difference between a novel and a brand instruction is, among other things, that the latter is openly goal-oriented. The goals can, admittedly, appear as very vague and general, but this is quite in line with the fluid character of the medium, as openness allows for flexible re-combinations and adjustment to different possible scenarios and objects of branding.

The sequence in PowerPoint presentations builds up a specific kind of narrative that makes up the generic distinctiveness of its narrative form. This also means that the narrative has a non-hierarchical and additive character, comparable with other 'flat' narratives where each individual segment is relatively independent of the preceding and succeeding segments, just the way in which news is presented in a newspaper (i.e. items are serialised in a specific order, but they could potentially be placed in any different order). Such narratives are also characteristic of a genre such as pornography, where, especially in feature films, the narrative units are self-contained and distributed within each segment, without them building an overarching story with a beginning, middle and end. The flat narrative does not arrive at narrative closure and, just as with pornography, this is functional as the open ending leaves the work of closure to the media user to fantasise about. The additive structure allows for the recombination of segments, adjustable to new contexts and makes the narrative structure more fluid, which also means that it loses the quality of producing 'in the meantime'-ness.

Beside the genre dimension, another representational difference between the novel and the phenomenon of branding is that the nationalist sentiment of the novelists (or landscape painters and music composers) is inscribed in their minds and bodies as an internalised sentiment. This is hardly the case with those that orchestrate nation branding campaigns and produce brand books, since their loyalty is not with the nation, but with the specific market in which they act (Ståhlberg and Bolin 2016). The nation builder does not need to repeatedly mention the name of the nation, since national sentiment runs deeper than that, whereas the nation brander works with constant repetition. This is also so because the nation brander has to convince 'you' who are not Ukrainian, Estonian, Polish or Indian and cannot be expected to have a deeply felt identification with the nation in question, whereas the nation builder is part of the 'we' addressed. As Anderson explains by reference to the Indonesian communist nationalist Mas Marco Kartodikromo and his novel Semarang Hitam: 'Marco feels no need to specify this community by name: it is already there' (Anderson 2006 [1991], 32).

Another way to put this is that nation branding seeks to manipulate desire, while nation building seeks to manipulate identities. What separates desire from identity is 
that desire is directed outwards, to an object outside of me, whereas identity is who I am. Where desire concerns things that can be achieved, we tend to think of identity and especially national identity, as something that just is. Its imaginary is supposedly already in place. Desire has a direction; identity is perceived as a state of being. In terms of inner essence, nation building deals with that which was, and now has to be restored, while nation branding is concerned with that which shall become a perception in the minds of others. The collective imaginary of a national past is then contrasted with the constructed image of the future.

All this has consequences for the functions that Anderson ascribes the novel and the newspaper: the ability to produce simultaneity and synchronisation. Just like the novel and the newspaper, PowerPoint is a cultural technology that allows for completely heterogeneous material to be assembled into one single form. Contrary to the novel, however, the stack of slides in a PowerPoint presentation does not produce a narrative that encourages social community. The presentations of a nation brand in PowerPoint form completely lack the temporal aspect 'in the meantime', which is a crucial component for Anderson in his argument for constructing simultaneous social communities. And despite its sharing with news the flat narrative structure, its lack of dating cannot produce the feeling among its recipients that other people in distant locations are 'reading' the PowerPointat at exactly the same time. Even if a presentation contains individual images, sentences or symbols that might evoke strong national feelings, it does not build up a narrative whole and the symbolic communication lacks the 'calendrical coincidence' that Anderson (2006 [1991], 33) considers to be foundational for offering emotional representations of 'a sociological organism moving calendrically through homogenous, empty time' (Anderson 2006 [1991], 26). Its fluidity does not guarantee that others are reading the same text as I am.

The reason why PowerPoint lacks the ceremonial quality of the newspaper and the novel is that it is not about ritual communication, but linear communication, the transmission of a set of ideas. Brand books usually are introduced with a clearly stated and openly pronounced aim, expected outcomes and a restricted target audience. No one would expect a novel to open like that. We would be very surprised indeed to open a novel and read about its expected outcomes, just as we would if the priest at Sunday mass would open the sermon by announcing the target audience for this week's sermon. In that sense, the ritual is dialogic, the branding exercise one-directional. This is strategic communication in line with a transmission model, rather than ritual communication that confirms community (cf. Carey 1975).

Just as with the ritual of the religious mass, ritual communication works at another level compared with Public Relations (PR) and branding. Ritual communication is about shared meaning and 'communification'. Its message is not on the level of the cognitive content, but on the deeper mythical level. Just as the media event it touches on is the 'basis of authority' by which society is integrated (Dayan and Katz 1992). Branding professionals do indeed strive to achieve the effects of ritual communication, but they rarely succeed (Ståhlberg and Bolin 2016). The tomb of an unknown soldier has the ritual quality of producing sentiments of belonging when 
we stand before it, but completely lose its emotional grip when appearing as one image among others in a stack of PowerPoint slides. In PowerPoint collections used for branding purposes, we often find several illustrations familiar from a nationalist imaginary (traditional folk costumes, art, monuments, cuisine, colours), but recontextualised for branding purpose and thus lacking all ritual qualities.

Furthermore, although the PowerPoint presentation is about synchronisation, it is not synchronising an audience taking part in a collective ritual of media consumption. Instead, PowerPoint is a technology that is useful for synchronising the production of a national brand, binding together actors from different spheres of society whose only common denominator is that they want to succeed in marketing a brand. Initially, it is usually with a PowerPoint presentation that a PR bureau pitches an idea to a customer, for example a national agency for tourism or a ministry of foreign affairs. And it is on this presentation that the customers may react and influence further developments. Thus, the cooperation between a client and a producer is synchronised through PowerPoint. PowerPoint is also central at the stage when a company needs to convince all other possible actors, both of the idea of nation branding in general and of the credibility of the particular work that they are doing. As many partners as possible need to be involved and cooperate and give input on key ideas that have to be outlined. Potentially, this could create a sense of sharing a project together, but hardly national sentiments. Finally, the brand book, with logotypes, designs and declarations of strategies is distributed in the form of a PowerPoint presentation throughout government agencies and private business in order to execute a synchronised campaign.

However, it is also this particular media technology that makes synchronisation of activities difficult since the form of the PowerPoint presentation is not stable, it is always in flux. Various versions of campaign material circulate among actors, since they are seldom removed from internet web pages. The actors also vary over time since the organisational forms of branding agencies are also always in flux, with different constellations of people from time to time, different company names, in yet more varying ways. Each project changes with every involved actor who makes some contribution, and individual slides can easily be reused in completely different contexts.

\section{Conclusion: What is the Role of Digital Media in National Imaginaries?}

Now, in what way does our analysis of the role of the PowerPoint presentation in the early stages of nation-branding efforts inform our understanding of contemporary imaginaries of the nation? In order to answer this, we need to return to Akhil Gupta's question about how later convergences between capitalism and media technologies might have changed the model of national imaginaries that Benedict Anderson understood as emanating from early print capitalism. As a response, we would argue that it has not left forms of imagining unaffected. Its true effect is the diversification of this imaginary, where digital media technologies, and most 
notably PowerPoint, are adopted to produce a branding market for the old imaginaries, moulding these, and the rhetoric of nation building, into consumer form. PowerPoint technology, which is the most important tool in the initial phases of the strategic communication of nation branding campaigns, is not a mass medium with the ability to transmit national narratives to broad audiences. Certainly, it is a tool for convincing, instructing and synchronising actors involved in producing nation brand images, but PowerPoint has very little to do with 'simultaneity' as the most essential concept in the wake of Anderson's theory of imagined communities, since the form of PowerPoint allows for very little opportunity of producing simultaneity, neither in the textual sense of 'in the meantime' narratives, nor in the ritualised act of national audiences being convinced of consuming the same identical content simultaneously. However, it is, just as with a museum, reproducing national symbols over time, utilising the repository of common national symbols that especially older nation states have accumulated in their invention of tradition, and hence it has the capacity to reproduce parts of the traditional national imaginary. The only morphological principle that the 'PowerPoint nation' has in common with the older form of national imagination produced with the technologies of print capitalism is what Benedict Anderson (1998) identified as unbounded seriality. Nationality, in this sense, becomes a universal category of modern thought, such as citizen, bureaucrat, worker, politician and so on. These are infinite categories, existing everywhere and, as such, offer possibilities for individuals to imagine themselves in a context larger than face-to-face. But unbounded seriality is not necessarily linked to political nationalism. It is also a principal that could be related to cosmopolitan forms of thought: the world consists of a potentially infinite number of nationalities and all of these could be imagined in the same form.

The fact that nation-branding campaigns are adopting the same signifiers as nation builders, then, does not mean that the imaginaries become the same. Although nation branders talk of constructing myths, they actually never arrive at the mythical level that would create a specific national community. In that sense, there is basically nothing behind the PowerPoint presentation; no deeper, mythical meaning of a specific nation to believe in. The idea of the nation as a social organism moving through history simply harmonises badly with the morphology of PowerPoint as a communication technology. What it does, however, is create a further imaginary, centred on the nation as an object of desire and on which anticipated value is projected, be it the value of the tourist experience or the economic value of return on investment. Far from being the nation as an imagined community, this is the nation as an 'imagined commodity'.

\section{References}

Adams S and Greutzner Robins A (2000) Introduction. In Adams S and Greutzner Robins A (eds), Gendering Landscape Art. Manchester: Manchester University Press, pp. 1-12.

Akhavan N (2014) Electronic Iran: The Cultural Politics of an Online Evolution. New Brunswick: Rutgers University Press. 
Anderson B (2006 [1991]) Imagined Communities: Reflections on the Origin and Spread of Nationalism, 2nd edn. London: Verso.

Anderson B (1998) The Spectre of Comparisons: Nationalism, Southeast Asia and the World. London: Verso.

Aronczyk M (2013) Branding the Nation. The Global Business of National Identity. Oxford: Oxford University Press.

Billig M (1995) Banal Nationalism. London: Sage.

Bohlman PV (2004) The Music of European Nationalism. Cultural Identity and Modern History. Santa Barbara: ABC Clio.

Bolin G and Ståhlberg P (2010) Between community and commodity. Nationalism and nation branding. In Roosvall A and Salovaara-Moring I (eds), Communicating the Nation. National Topographies of Global Media Landscapes. Göteborg: Nordicom, pp. 79-101.

Bolin G and Ståhlberg P (2015) Mediating the nation state: The role of 'the media' in nation branding campaigns. International Journal of Communication 9, 3065-3083.

Carey J (1975) A ritual approach to communication. Communication 2(1), 1-22.

Das R, Kleut J and Bolin G (2013) New genres - new roles for the audience? An overview of recent research. In Carpentier N, Schröder K and Hallett L (eds), Audience Transformations. Shifting Audience Positions in Late Modernity. London: Routledge, pp. 30-46.

Dayan D and Katz E (1992) Media Events: The Live Broadcasting of History. Cambridge, MA; London: Harvard University Press.

Eriksen, TH (2007) Nationalism and the internet. Nations and Nationalism 13(1), 1-17.

Gellner E (1983) Nations and Nationalism. Oxford: Blackwell.

Gupta A (2008) Imagining nations. In Nugent D and Vincent J (eds), Companion to the Anthropology of Politics. Malden, MA: Wiley, pp. 267-281.

Hobsbawm E and Ranger T (eds) (1983) The Invention of Tradition. Cambridge: Cambridge University Press.

Kaneva N (ed.) (2012) Branding Post-Communist Nations. Marketizing National Identities in the 'New' Europe. New York; London: Routledge.

Kernbach S, Bresciani S and Eppler M (2015) Slip-sliding away: areview of the literature on the constraining qualities of PowerPoint. Business and Professional Communication Quarterly 78(3), 292-313.

Kjeldsen J (2006) The rhetoricof PowerPoint. International Journal of Media, Technology and Lifelong Learning 2, 1-17.

Knoblauch H (2008) The performance of knowledge: pointing and knowledge in PowerPoint presentations. Cultural Sociology 2(1), 75-97.

Mihelj S (2011) Media Nations: Communicating Belonging and Exclusion in the Modern World. Houndmills: Palgrave Macmillan.

Ong W (2002 [1982]) Orality and Literacy: The Technologizing of the Word. London; New York: Routledge.

Pettitt T (2007) Before the Gutenberg parenthesis: Elizabethan-American compatibilities. Keynote address at the Media in Transition 5 Conference, MIT, Cambridge, MA. http://web.mit.edu/comm-forum/mit5/papers/pettitt_plenary_gutenberg.pdf.

Soffer $\mathbf{O}$ (2013) The internet and national solidarity: atheoretical analysis. Communication Theory 23(1), 48-66.

Ståhlberg P and Bolin G (2016) Having a soul or choosing a face? Nation branding and the concept of 'identity'. Social Identities 22(3), 274-290.

Stark D and Paravel V (2008) PowerPoint in public: digital technologies and the morphology of demonstration. Theory, Culture \& Society 25(5), 30-55. 
Surowiec P (2016) Nation Branding, Public Relations and Soft Power. London; New York: Routledge.

Taylor C (2002) Modern social imaginaries. Public Culture 14(1), 91-124.

Therwath I (2012) Cyber-hindutva: Hindu nationalism, the diaspora and the web. Social Science Information 51(4), 551-577.

Tufte ER (2003) The Cognitive Style of PowerPoint. Cheshire, CT: Graphics Press.

Valaskivi K (2016) Cool Nations. Media and the Social Imaginary of the Branded Country. London: Routledge.

Volcic Z and Andrejevic M (eds) (2015) Commercial Nationalism: Selling the Nation and Nationalizing the Sell. Houndmills: Palgrave Macmillan.

Yates J and Orlikowski W (2007) The PowerPoint presentation and its corollaries: how genres shape communicative action in organisations. In Zachry $\mathbf{M}$ and Thralls C (eds), Communicative Practices in Workplaces and the Professions: Cultural Perspectives on the Regulation of Discourse and Organisations. Amityville, NY: Baywood Publishing, pp. 67-92.

\section{About the Authors}

Göran Bolin is Professor of Media \& Communication Studies at Södertörn University, Stockholm, Sweden.

Per Ståhlberg is Associate Professor of Media \& Communication Studies at Södertörn University, Stockholm, Sweden. 